\title{
Pemberdayaan Masyarakat Dengan Pendekatan Peer Group Support Dalam Penanganan Sadar TB di Puskesmas Rumbai Pesisir
}

\author{
Nia Khusniyati, Wiwiek Delvira, Yusniman Roni \\ Prodi DIII Keperawatan, Poltekkes Kemenkes Riau \\ Email: nia@pkr.ac.id, wiwiek@pkr.ac.id
}

\begin{abstract}
Abstrak
Kepatuhan penderita TB tuberkulosis dalam menjalani pengobatan merupakan hal utama dalam keberhasilan pengobatan. Dukungan sosial dari keluarga dan teman-teman kelompok pendukung dapat dibentuk untuk membantu kepatuhan pasien dalam menjalani pengobatan. Adapun bentuk dukungan yang dapat diberikan kepada penderita TB penderita tuberkulosis paru adalah dalam bentuk peer group support yang dapat berupa dukungan positif pada setiap kegiatan yang dilakukan. Pengabdian dilaksanakan di Puskesmas Rumbai Pesisir yang terdiri dari 20 Kader Kesehatan pada tahun 2020. Metode dalam melaksanakan kegiatan ini melalui pelatihan yakni dengan memberikan pengetahuan melalui ceramah interaktif kemudian diberikan keterampilan mengenai bagaimana kader kesehatan melakukan peer group support terhadap pasien TB. Adapun manfaat yang dihasilkan dari kegiatan ini adalah Kader kesehatan TB memiliki perubahan pada pengetahuan, pemahaman, dan keterampilan Kader Kesehatan dalam menangani pasien TB. Peer group support seharusnya dilakukan secara keberlanjutan sehingga meningkatkan motivasi pasien TB dalam kepatuhan minum obat agar sembuh. Dengan adanya peer group support ini pasien TB tidak akan merasa sendiri dan depresi karena bisa berbagi cerita dalam menghadapi penyakit TB.
\end{abstract}

Kata Kunci : TB, peer group support, kepatuhan minum obat, kader kesehatan

\begin{abstract}
The adherence of TB patients in undergoing treatment is the main thing in the success of treatment. Social support from family and friends support groups can be formed to assist patient compliance in undergoing treatment. The form of support that can be given to TB patients with pulmonary tuberculosis is in the form of peer group support which can be in the form of positive support for every activity carried out. The service is carried out at the Rumbai Pesisir Health Center which consists of 20 Health Cadres in 2020. The method in carrying out this activity is through training, namely by providing knowledge through interactive lectures and then providing skills on how health cadres perform peer group support for TB patients. The benefits resulting from this activity are TB health cadres have a change in the knowledge, understanding, and skills of Health Cadres in dealing with TB patients. Peer group support should be carried out on an ongoing basis so as to increase the motivation of TB patients in taking medication adherence to recover. With this peer group support, TB patients will not feel alone and depressed because they can share stories in dealing with TB disease.
\end{abstract}

Keywords : TB, peer group support, medication adherence, health cadres

http://ejournal.urindo.ac.id/index.php/PAMAS

Article History :

Submitted 04 Mei 2021, Accepted 29 Oktober 2021, Published 31 Oktober 2021 
Jurnal Pelayanan dan Pengabdian Masyarakat (PAMAS)

\section{PENDAHULUAN}

Tingginya kasus penyakit tuberkulosis di Indonesia berbanding terbalik dengan tingkat kepatuhan dalam minum obatnya. Menurut Riskesdas tahun 2018 didapatkan hasil bahwa penderita TB di Indonesia mencapai 511.873 penderita TB. Dan data penderita TB di Provinsi Riau sebanyak 11.135. Dari 20 Puskesmas yang tersebar di Kota Pekanbaru salah satunya Puskesmas Rumbai teridentifikasi penderita TB suspek sebanyak 123 orang dan positif TB sebanyak 13 orang. Adapun salah satu faktor yang sangat mempengaruhi tingginya angka tersebut adalah kepatuhan minum obat. Penderita TB yang melakukan kepatuhan minum obat dapat meningkatkan derajat kesehatan terhadap penyakitnya dan mendapatkan hasil yang baik selama proses pengobatan (Nugroho 2013). Oleh karena itu, selama penderita TB dapat meningkatkan kepatuhan dalam minum obat maka penderita harus diberikan dukungan dari keluarga, masyarakat, dan lingkungan sekitar (Hiswani 2015).

Dalam pelaksanaan penanggulangan sadar TB dibutuhkan adanya peran dari masyarakat sehingga masyarakat dapat diberdayakan dalam penanggulangan sadar TB. Pemberdayaan masyarakat dalam hal ini adalah segala upaya fasilitasi yang bersifat musyawarah, guna meningkatkan kemampuan dan pengetahuan masyarakat agar mampu mengidentifikasi masalah yang dihadapinya, kemudian potensi yang dimiliki serta merencanakan dan menyelesaikan dengan memanfaatkan potensi yang dimiliki masyarakat setempat (Kemkes, 2015). Pemberdayaan dalam bidang kesehatan dalam hal ini adalah penanggulangan sadar TB yang bertujuan untuk meningkatkan tingkat kesembuhan pada penderita TB bermitra dengan fasilitator yakni pemerintah, tenaga kesehatan dan LSM. Tenaga kesehatan dalam hal ini salah satunya dalah Puskesmas. Dalam tatanan Puskesmas dalam penanggulangan sadar TB diperlukan adanya penanggung jawab TB (PJ TB) yang berfungsi untuk mengumpulkan data masyarakat yang terkena TB. Dalam pelaksanaan tugasnya PJ TB dibantu oleh kader kesehatan.

Kader kesehatan merupakan tenaga yang berasal dari masyarakat yang dipilih oleh msyarakat dan bekerja sama untuk masyarakat secara sukarela (Ismawati, 2010). Kader kesehatan merupakan salah satu masyarakat yang dapat memberikan dukungan pada penderita TB. Kader kesehatan berfungsi untuk melakukan investigasi kontak penderita TB sampai dengan pemantauan minum obat (PMO) penderita TB.

Adapun dukungan yang dapat diberikan kepada penderita TB penderita tuberkulosis paru adalah peer group support berupa dukungan positif pada setiap kegiatan penderita lakukan. Al-Mighwar (2006) berpendapat bahwa adanya pengaruh teman sebaya terhadap tingkah laku, minat, dan sikap yang lebih besar dibandingkan pengaruh dari keluarga. Milgram (dalam Wade dan Tavris 2007) menyatakan ketika subjek/penderita bekerja dengan teman-teman dekatnya atau berada dalam lingkungan yang sama, maka subjek/penderita akan melakukan yang dilakukan pula oleh teman- 
temannya, baik itu sikap patuh maupun tidak. Peer group support telah dilakukan pada tim pengabmas sebelumnya dan berdampak positif terhadap kemajuan kesehatan penderita TB. Peer group support berpengaruh terhadap tingkat kepatuhan minum obat pada penderita TB TB paru (Alfid 2016).

\section{METODE}

Adapun metode pelaksanaan kegiatan pendekatan peer group support dalam penanganan sadar TB dilaksanakan dengan cara tatap muka dengan memperhatikan protokol kesehatan Covid 19. Pelaksanaan kegiatan ini dengan melakukan pemberian 3 materi yaitu 3 teori dan 1 praktikum. Adapau materi yang diberikan adalah perihal tentang Tuberkulosis terkait penyakit, cara pengobatan, dan cara pemeriksaan, dilanjutkan dengan materi perihal peran dan fungsi kader, dan selanjutnya tentang peer gorup support baik teori maupun praktek tentang peer group support. Materi teori ini dilakukan sebanyak 3 kali pertemuan, yang mana sebelum pemberian materi dilakukan pretest terlebih dahulu. Setelah teori sudah selesai kemudian diberikan praktik peer group support. Setelah itu dilakukan pelatihan cara pendidikan kesehatan atau penyuluhan kesehatan dan peer group support. Praktik ini melibatkan pasien TB yang sudah sembuh, sedang menjalani pengobatan serta pasien yang baru terdiagnosa TB. Setelah selesai maka dilakukan posttest untuk mengetahui tingkat pengetahuan dan pemahaman kader kesehatan selama mengikuti kegiatan tersebut.

\section{HASIL DAN EVALUASI}

Adapun hasil yang telah tercapai dalam kegiatan pengabdian kepada masyarakat dengan jenis Pengabmas Kemitraan Masyarakat adalah sebagai berikut:

Tabel 1.

Perbandingan rata-rata nilai Pengetahuan Kader berdasarkan Hasil Pretest dan Post test

\begin{tabular}{|c|c|c|c|}
\hline No & Pengetahuan tentang Materi & $\mathbf{n}$ & mean \\
\hline 1 & Pretest & 20 & 68 \\
\hline 2 & Post test & 20 & 83 \\
\hline
\end{tabular}

Pada tabel 1 dapat dilihat bahwa rata-rata nilai pengetahuan kader tentang materi TB, Peran dan fungsi kader, serta peer group support, sebelum dan sesudah dilakukan pembekalan materi mengalami peningkatan yaitu dari rata-rata nilai 68 menjadi rata-rata 83 . Nilai yang dihasilkan pada posttest sangat memuaskan. 
Tabel 2.

Distribusi Kader Posyandu berdasarkan Usia

\begin{tabular}{ccccc}
\hline No & & Usia & $\mathbf{n}$ & \% \\
\hline 1 & $<30$ tahun & & 0 & 0 \\
\hline 2 & $30-45$ tahun & & 16 & 80 \\
\hline 3 & $>45$ tahun & & 4 & 20 \\
\hline & & Jumlah & 20 & 100 \\
\hline
\end{tabular}

Pada tabel 2 dapat dilihat bahwa sebagian besar kader posyandu berusia 30-45 tahun dengan persentase yaitu $80 \%$ (16 orang).

Hasil analisis dari pelaksanaan pengabdian masyarakat ini menunjukkan adanya perbedaan pengetahuan sebelum dilaksanakan pengabmas dan setelah dilakukan kegiatan pengabmas. Hasil dari kegiatan pengabmas ini menunjukkan hasil uji statistik mean yakni ada perubahan yang signifikan pada penegtahuan kader kesehatan perihal materi TB, peran dan fungsi kader, dan peer group support. Hal ini sejalan dengan penelitian Alfid (2016) bahwa peer group support sangat mempengaruhi terhadap sikap dan penegtahuan pada penderita tuberculosis paru dan berdampak positif terhadap kepatuhan minum obat pada pasien TB yang sedang menjalani pengobatan. AlMighwar (2006) menyatakan bahwa pengaruh teman sebaya terhadap tingkah laku, sikap, dan minat memiliki lebih besar pengaruhnya dari pada pengaruh dari keluarga. Suatu sikap dapat belum dipastikan dapat terwujud dalam suatu tindakan. Untuk mewujudkan sikap itu menjadi perbuatan yang nyata diperlukan faktor pendukung atau suatu kondisi yang memungkinkan antara lain adalah fasilitas dan dukungan kelompok (Notoatmodjo, 2010). Hasil akhir dari pelaksanaan pengabdian masyarakat ini adalah adanya peningkatan pemahaman dan pengetahuan kader kesehatan terhadap peer group support yang dapat diterapkan pada pasien TB dalam rangka penanganan sadar TB. Dengan adanya peer group support maka pasien TB diharapkan dapat meningkatkan kepatuhan minum obat sehingga dapat sembuh. Sejalan dnegan hasil penelitian Hasanah (2017) Hasil pengabams peer group support ini berdampak positif terhadap responden dimana terjadi peningkatan kepatuhan pada pengobatan, hal ini senada dengan dengan penelitian Milgram (2007) menjelaskan bahwa, ketika subjek bercerita dan berkomunikasi dengan teman-teman dekatnya atau berada dalam lingkungan yang sama, maka subjek akan melakukan apa yang dilakukan pula oleh 
oleh teman- temannya.

\section{KESIMPULAN}

Adanya peningkatan pengetahuan dan pemahaman kader perihal peer group support dalam penanggulangan sadar TB dan dengan dilakukannya peer group support ini maka terbentuklah suatu kelompok antara penanggung jawab TB, kader kesehatan, dan pasien TB di Puskesmas Rumbai Pesisir. Kelompok tersebut dengan membentuk group media sosial berupa whatsapp yang mana untuk mempermudah koordinasi selama pandemi covid-19 dan dapat melakukan sharing melalui media sosial tersebut.

\section{DAFTAR PUSTAKA}

1. Alfid. 2016. Pengaruh Peer Group Support Terhadap pengetahuan, Sikap, kepatuhan Minum Obat dan Kualitas Hidup Klien Tuberkulosis paru, Tesis Fakultas Keperawatan Universitas Airlangga

2. Al-Mighwar, M, 2006, Psikologi Remaja. Bandung: CV Pustaka setia

3. Hasanah, Uswatun. 2017. Pengaruh PEER Group Support terhadap tingkat kepatuhan pengobatan pada klien tuberculosis paru di Wilayah Kerja Puskesmas Klampis Bangkalan. Universitas Airlangga: Surabaya

4. Hiswani, 2004, Tuberkulosis Merupakan Penyakit Infeksi YangMasih Menjadi Masalah Kesehatan Masyarakat, Fakultas Kesehata Masyarakat Universitas Sumatera.

http://library.usu.ac.id/download/fkm/fkm- hiswani12.pdf,

5. Kemenkes RI. 2018. Data dan Informasi : Profil Kesehatan Indonesia 2018.

6. Nugroho, M, A, 2013, Perbedaan Kepatuhan Minum Obat Penderita Tuberkulosis Antara Yang Menggunakan Layanan Pesan Singkat Dengan Pengawas Minum Obat di Puskesmas Dinoyo Malang

7. Notoatmodjo, Soekidjo. 2003, Pendidikan dan Perilaku Kesehatan. Jakarta: PT. Rineka Cipta

8. Wade, C., dan Tarvis, C. 2007. Psikologi. Edisi 9. Terjemahan Benedictine Widyasinta dan Darma Juwono. Jakarta: PT Erlangga 